derbyshire.eolcare.uk) was launched in October 2015. As well as a library of resources, the website offers users the option to create an individualised learning portfolio. This can be linked to existing accredited resources (eELCA) as well as signposting to local face to face educational events.

Results In the period 1.10.2016-30.9.2017, 9862 sessions were conducted on our website, by 5842 users. The average number of pages viewed per session was 3.6 with an average session duration being 3'34 'More than 50\% of users in this period were new to the website and our low bounce rate suggests that people who came to us found what they were looking for. The most popular resource was symptom management guidance.

Conclusions This novel website is a well-used platform for a suite of resources, as well a means of educational support for those engaging in end of life care.

\section{IMPROVING PALLIATIVE CARE AND ADVANCE CARE PLANNING IN END STAGE HEART FAILURE IN A GENERAL HOSPITAL SETTING}

Lori Low, Constantina Pitsillides, Oscar Evans, Eleanor Smith, Adrian Scott, Soon Song. Sheffield Teaching Hospitals

\subsection{6/bmjspcare-2018-ASPabstracts.137}

Background Advance care planning (ACP) is an integral part in the management of end stage heart failure (HF). This is often poorly done in medical wards. To improve this aspect of care, we focussed on discussions with patients and their families regarding prognosis and ceiling of care, explored patients' wishes for end of life care including hospital admission avoidance, liaised with palliative care team on pre-emptive medications for treatment in community and communicated with GPs on advance care management. This study presents the outcomes of these interventions.

Methods End stage HF was defined as patients with severe refractory symptoms (New York Heart Association class 3 and 4) despite optimal medical treatment. This diagnosis was confirmed by echocardiogram and clinical assessment by $\mathrm{HF}$ team. The following interventions were used to improve ACP: training at departmental induction meeting to identify end stage HF patients;

medical teams encouraged to initiate ACP discussions; poster to remind junior doctors of the relevant information to include in discharge summaries to GP

Data were extracted from medical records and discharge summaries to assess the impact of these interventions.

Results Data were collected from 63 patients between August 2016 and March 2017. Discussions on prognosis and ceiling of care improved from $8.6 \%$ to $25.0 \%$ and $14.3 \%$ to $28.5 \%$ respectively. There was better communication to GPs on inpatient $(2.8 \%$ to $21.4 \%)$ and community $(8.6 \%$ to $21.4 \%)$ palliative management. Pre-emptive medication prescribing increased from $8.6 \%$ to $14.3 \%$. There was discrepancy in ACP documentation in medical records vs discharge summaries (38.1 vs $25.0 \%)$.

Conclusions Despite improvement in ACP and its communication to primary care, significant gaps still exist. This study highlights the challenges in implementing this aspect of care in acute medical setting. Innovative strategies at trust organisational level are needed to deliver this care more effectively.
111 THE EPIDEMIOLOGY OF THE OUT OF HOURS GENERAL PRACTIONER'S PALLIATIVE WORKLOAD IN SHROPSHIRE

MP Doré, D Willis. Severn Hospice, University of Chester

\subsection{6/bmjspcare-2018-ASPabstracts. 138}

Introduction There is a paucity in information or standards regarding palliative care being performed by the general practioner (GP) out of hours $(\mathrm{OOH})$. The need for evidence is pressing as discussions are held as to whether 24 hour specialist palliative care cover is required, or whether generalists are capable of dealing with emergency $\mathrm{OOH}$ palliative care.

Aim This poster seeks to provide evidence for this discussion by outlining the patient's demographics, the GP's workload, social issues and symptomology encountered. By quantifying the current challenges faced, we can focus on defining what is needed in the future.

Methodology Using Shropshire Doctors Co-operative Ltd (Shropdoc's) recorded data we have collated a representative picture of the palliative care practice over a year period from 161 OOHGP interactions.

Results Palliative care makes $11.5 \%$ of the total OOHGP Home Visits (HV). There is a positively skewed distribution with a median age 81 with $56 \%$ female. Saturday followed by Sunday are the most active days with more HV over the weekend than the rest of the week combined. Overall $56 \%$ of OOHGP HV are for patients who are expected to die within the next 48 hours with $80 \%$ of the symptoms being agitation, secretions and pain in this group. Social issues were documented in $21 \%$ of $\mathrm{HV}$ with multiple concerns highlighted, however adjusting for a prognosis estimated less than 48 hours the focus shifted to family distress ( $3 \mathrm{x}$ more likely) and future planning (5x more likely).

Conclusion The greatest demand is all weekend and from 17:00-21:00 throughout the week. These finding could provide weighting to arguments of provisions of $\mathrm{OOH}$ care. The patients seen are appropriate and the symptomology encountered is heterogeneous but the majority can be distilled to end-of-life emergency symptoms. This highlights the varied and predictable unpredictability of palliative care and a largely unrecognised contribution to social-care and future-planning $\mathrm{OOH}$.

\section{THE TREATMENT, INTERVENTIONS AND HOSPITAL ADMISSIONS AS PART OF THE OUT OF HOURS GENERAL PRACTIONER'S PALLIATIVE WORKLOAD IN SHROPSHIRE}

MP Doré, D Willis. Severn Hospice, University of Chester

10.1136/bmjspcare-2018-ASPabstracts. 139

Introduction There is a paucity in information or standards regarding palliative care being performed by the general practioner (GP) out of hours $(\mathrm{OOH})$. The need for evidence is pressing as discussions are held as to whether 24 hour specialist palliative care cover is required, or whether generalists are capable of dealing with emergency $\mathrm{OOH}$ palliative care.

Aim This poster seeks to provide evidence for this discussion by outlining treatments instigated, interventions made and hospital admissions arranged $\mathrm{OOH}$. By quantifying the challenges faced, we can define what is needed in the future 